\title{
Clinical Profile of Birth Asphyxia in Dhulikhel Hospital: A Retrospective Study
}

\author{
Dongol $\mathrm{S}^{1}$, Singh $\mathrm{J}^{2}$, Shrestha $\mathrm{S}^{2}$, Shakya $\mathrm{A}^{3}$ \\ ${ }^{1}$ Dr. Srijana Dongol,MBBS.MD. Lecturer, Department of Paediatrics, ${ }^{2}$ Dr. Jeevan Singh, MBBS. MD, Assistant Professor, \\ Department of Anaesthesia, ${ }^{2}$ Shrima Shrestha, MBBS.MD. Lecturer Department of Paediatrics, ${ }^{3}$ Dr. Amir Shakya, MBBS, \\ Department of Paediatrics, Kathmandu University School of Medical Sciences (KUSMS), Dhulihel Kavre, Nepal.
}

Correspondence Address: Dr. Srijana Dongol, E-mail : docsrijana@yahoo.com

\begin{abstract}
Introduction: Birth asphyxia is defined by the World Health Organization "the failure to initiate and sustain breathing at birth." The WHO has estimated that 4 million babies die during the neonatal period every year and $99 \%$ of these deaths occur in low-income and middle income countries. Three major causes account for over three quarters of these deaths, serious infection $(28 \%)$ complication of preterm birth $(26 \%)$ and birth asphyxia $(23 \%)$. This estimation implies that birth asphyxia is the cause of around one million neonatal deaths each year. One of the present challenges is the lack of a gold standard for accurately defining birth asphyxia. Because of same reason the incidence of birth asphyxia is difficult to quantify. Objective: The aim of this study was to assess the prevalence of birth asphyxia, identify the common obstetric and neonatal risk factors, and study the cause of death. Methodology: All babies born in Dhulikhel Hospital (DH) from Jan 2007 to Oct 2009 with a diagnosis of birth asphyxia (5 min Apgar $<7$ and those with no spontaneous respirations after birth) were included in the study $(n=102)$. Clinical information was collected retrospectively from maternal records (maternal age, gravida, type of delivery, presence of meconium, induced or spontaneous labour, and pregnancy complications). The NICU records provided additional information about new born infant (birth asphyxia, stages of birth asphyxia, birth weight, sex and subsequent mortality). Results: Among the 3784 live births there were 102 babies with birth asphyxia prevalence of 26.9/1000 live births. Babies with Hypoxic ischemic encephalopathy (HIE) Stage 1 had a very good outcome but HIE III was associated with a poor outcome. Males, primipara and pregnancies with complications were associated with a higher rate of birth asphyxia. Septicaemia, necrotizing enterocolitis, preterm delivery, convulsion and, pneumothorax were associated with higher mortality and morbidity. Conclusion: Birth asphyxia was one of the commonest causes of admission and mortality in NICU. Babies with HIE Stage III had a very poor prognosis. Birth asphyxia combined with other morbidities was associated with a higher mortality. Sepsis is the commonest morbidity in cases of birth asphyxia. Maternal gravida, pregnancy complication with PROM, meconium, APH, emergency caesarean section, preterm and male sex were the risk factors for birth asphyxia.
\end{abstract}

Key words: Birth asphyxia, HIE, Neonatal sepsis

\section{Introduction}

B th asphyxia is defined by the World Health Organization "the failure to initiate and sustain breathing at birth."1 The National Neonatology Forum of India has defined birth asphyxia as" gasping and ineffective breathing or lack of breathing at one minute after birth. The $\mathrm{WHO}$ has estimated that 4 million babies die during the neonatal period every year and
$99 \%$ of these deaths occur in low-income and middle income countries ${ }^{2}$. Three major causes account for over three quarters of these deaths, serious infection (28\%) complication of preterm birth (26\%) and birth asphyxia $(23 \%)^{2}$. These estimation imply that birth asphyxia is the cause of around one million neonatal deaths each year. One of the present challenges is the lack of a gold 
standard for accurately defining birth asphyxia. Because of same reason the incidence of birth asphyxia is difficult to quantify. This is demonstrated by the difference in occurrence according to different studies, where the incidence ranges from 5.4/1000 live births in a Swedish study $^{3}$ to $22 / 100$ live hospital births in an Indian study. ${ }^{4,5}$

The incidence of asphyxia in full term infants varies between 2.9-9.0 cases per thousand in industrial countries. The incidence for birth asphyxia is much higher in developing countries ${ }^{6}$. Hospital based studies in $\mathrm{Nepal}^{7}$ and South Africa ${ }^{8}$ estimated that birth asphyxia accounted for $24 \%$ and $14 \%$ of perenatal mortality respectively. However, these may substantially underestimate the burden in rural areas, where early deaths, most of which occur at home, and more likely to be under reported.

Asphyxia, a lack of oxygen or an excess of carbon dioxide caused by the interruption in breathing, is the result of the failure of the gas exchange organ. There are many reasons a baby may not be able to take oxygen before, during or just after birth. A mother may have medical conditions that can lower her oxygen levels, there may be problem with the placenta that prevents enough oxygen from circulating to the fetus or the baby may be unable to breath after delivery. In mild HIE, muscle tone may be increased slightly and deep tendon reflexes may be brisk during first few days. Transient behavioral abnormalities such as poor feeding, irritability excessive crying or sleepiness may be observed. In moderately severe HIE, the infant is lethargic with significant hypotonia, and diminished deep tendon reflexes. The grasping, Moro and sucking reflexes may be sluggish or absent, seizures may occur within 24 hrs of life. In severe HIE, stupor or coma is typical. The infant may not respond to any physical stimulus. Breathing may be irregular and the infant often requires ventilatory support. Generalized hypotonia and depressed deep tendon reflexes are common. Pupils may be diluted, fixed or poorly reactive to light, seizures occurs early and may be initially resistance to conventional treatments ${ }^{9}$.

At Dhulikhel Hospital, the incidence rates of birth asphyxia for the years 2007, 2008, 2009 till Oct were 24, 23, 34 per 1000 live births respectively.

The aim of present study was to identify the prevalence of birth asphyxia and of avoidable risk factors for neonatal encephalopathy including mortality due to birth asphyxia. Risk factors for birth asphyxia in hospital based setting in developing countries have been categorized into ante partum, intrapartum and post natal characteristics. In this study, we identify risk factors for birth asphyxia among newborns born in Dhulikhel hospital from data collected retrospective with all mothers from birth asphyxia babies

\section{Materials and Methods}

The study was a retrospective study on newborns with the diagnosis of birth asphyxia at Dhulikhel Hospital, Kathmandu University Teaching Hospital (KUTH), Kavre, Nepal. Dhulikhel Hospital is a University hospital in collaboration with Kathmandu University located in Dhulikhel in Kavre district. This is a tertiary level hospital with a well equipped and established Paediatric department including Neonatal Intensive Care Unit (Level-III) and Paediatric Intensive Care Unit facility.

A total of 102 consecutive asphyxiated newborn who met the inclusion criteria were enrolled in the study. All newborn babies with a clinical diagnosis of birth asphyxia (newborn with history of delayed cry or APGAR score of less than 7 in 5 minutes) were included in the study.

The four categorical determinants that were considered were as follows: pregnancy complications, use of induction of labour (none, oxytocin, misoprostol or both), type of delivery (normal, caesarean and vaccum) and sex of baby. In addition, five continuous determinants were measured which were as follows: age, number of antenatal (ANC) visits, gestational age, gravida and birth weight. The outcome of birth asphyxia in respect of mortality in different stage of HIE were also determined.

\section{Results}

Between Jan 2007 and Oct 2009, there were 3784 live births in Dhulikhel Hospital, of whom 719 new born infants were admitted to NICU and 56 babies died. The mortality rate was therefore $7.7 \%$ of those admitted to NICU and $1.4 \%$ of all live births.

The 102 cases of birth asphyxia accounted for $14 \%$ of NICU admissions. There were more males than females $57(55.88 \%)$ and $45(44.12)$ respectively overall except in the HIE 2 category where females outnumbered males.

It is seen in Table 2 that the incidence of birth asphyxia was most commonly associated with maternal age between 18-35years, antenatal care in $\mathrm{DH}$, term pregnancy, primy gravid women. It was also more common after emergency LSCS, thick meconium and premature rupture of membranes. 
The total NICU admission during this study period was 719. Among them 57(7.92\%) died. Among all different causes for mortality in NICU, birth asphyxia accounted for $28.07 \%$. The mortality in HIE stage I were $2(2.50 \%)$, HIE stage II were $5(33.33 \%)$ and HIE stage III were $9(90 \%)$. The recovery rate of birth asphyxia in HIE stage I, HIE stage II and HIE stage III were $97.40 \%$, $66.66 \%$ and $10 \%$ respectively.

There were total 16 cases $(15.67 \%)$ of birth asphyxia that died during this study period. In HIE stage I mortality and morbidity were very rare and sepsis and preterm were common morbidity in this stage. There were a total of 5 deaths in HIE stage II. Among them $4(26.66 \%)$ had neonatal sepsis and 1 case had hydrocephalus. There were a total 9 deaths in HIE stage III. Among them 4 (44.44\%) cases were associated morbidities like neonatal sepsis, two cases $(22.22 \%)$ had neonatal sepsis with pneumothorax. Another 2 (22.22\%) were preterms with hyaline membrane disease and 1 $(11.11 \%)$ had meconium aspiration syndrome. Neonatal sepsis is the commonest morbidity in all stages of Birth asphyxia.

Table 1: Showing total number of neonates with birth asphyxia $(n=102)$.

\begin{tabular}{|l|c|c|c|c|c|c|}
\hline Presentation & Male & \% & Female & \% & Total & $\%$ \\
\hline HIE I & 42 & 54.54 & 35 & 45.45 & 77 & 75.49 \\
\hline HIE II & 7 & 46.66 & 8 & 53.33 & 15 & 13.72 \\
\hline HIE III & 8 & 80 & 2 & 20 & 10 & 9.80 \\
\hline Grand Total & $\mathbf{5 7}$ & & $\mathbf{4 5}$ & & $\mathbf{1 0 2}$ & \\
\hline
\end{tabular}

Table 2: Showing distribution of determinants associated with birth asphyxia.

\begin{tabular}{|c|c|c|c|}
\hline Determinants & Category & Number $(n=102)$ & Percent (\%) \\
\hline Maternal age & $\begin{array}{l}<18 \text { years } \\
18-35 \text { years } \\
>35 \text { years }\end{array}$ & $\begin{array}{l}12 \\
80 \\
10\end{array}$ & $\begin{array}{c}11.76 \\
78.43 \\
9.8\end{array}$ \\
\hline ANC visit & $\begin{array}{l}\text { Dhulikhel hospital } \\
\text { Health post } \\
\text { none }\end{array}$ & $\begin{array}{l}62 \\
24 \\
16\end{array}$ & $\begin{array}{c}60.7 \\
23.52 \\
15.68 \\
\end{array}$ \\
\hline Gestational Age & $\begin{array}{l}<37 \text { weeks } \\
37-42 \text { weeks } \\
>42 \text { weeks }\end{array}$ & $\begin{array}{c}20 \\
78 \\
4\end{array}$ & $\begin{array}{c}19.60 \\
78.47 \\
3.92\end{array}$ \\
\hline Gravida & $\begin{array}{l}1 \\
2-4 \\
>4\end{array}$ & $\begin{array}{c}60 \\
36 \\
6\end{array}$ & $\begin{array}{c}58.82 \\
35.29 \\
5.88\end{array}$ \\
\hline Pregnancy Complications & $\begin{array}{l}\text { Prolapsed } \\
\text { Heart disease } \\
\text { Fetal anomaly } \\
\text { Thick meconium } \\
\text { Infection } \\
\text { Pre-eclampsia } \\
\text { APH } \\
\text { Placenta previa } \\
\text { Hypertension } \\
\text { PROM }\end{array}$ & $\begin{array}{c}1 \\
3 \\
2 \\
38 \\
12 \\
7 \\
16 \\
4 \\
2 \\
21\end{array}$ & $\begin{array}{c}0.98 \\
2.94 \\
1.96 \\
37.25 \\
11.76 \\
6.8 \\
15.68 \\
3.92 \\
1.96 \\
20.58\end{array}$ \\
\hline Induction of Labour & \begin{tabular}{|l|} 
Done \\
Not done
\end{tabular} & $\begin{array}{l}28 \\
74\end{array}$ & $\begin{array}{l}27.45 \\
72.54\end{array}$ \\
\hline Mode of Delivery & $\begin{array}{l}\text { Spontaneous } \\
\text { Vaccum } \\
\text { c-section }\end{array}$ & $\begin{array}{c}53 \\
9 \\
40\end{array}$ & $\begin{array}{c}51.96 \\
8.82 \\
39.21\end{array}$ \\
\hline Birth weight & $\begin{array}{l}<2500 \mathrm{~kg} \\
2500-3000 \mathrm{~kg} \\
>3000 \mathrm{~kg}\end{array}$ & $\begin{array}{l}31 \\
51 \\
20\end{array}$ & $\begin{array}{c}30.39 \\
50 \\
19.60\end{array}$ \\
\hline Sex & $\begin{array}{l}\text { Male } \\
\text { Female }\end{array}$ & $\begin{array}{l}57 \\
45\end{array}$ & $\begin{array}{l}55.88 \\
44.11\end{array}$ \\
\hline
\end{tabular}


Table 3: Showing the outcome of treatment in babies with birth asphyxia.

\begin{tabular}{|l|l|l|l|}
\hline Stages & HIE I (77) & HIE II (15) & HIE III (10) \\
\hline Recovery & $75(97.40 \%)$ & $10(66.66 \%)$ & $1(10 \%)$ \\
\hline Death & $2(2.50 \%)$ & $5(33.33 \%)$ & $9(90 \%)$ \\
\hline
\end{tabular}

Table 4: Showing morbidity and mortality in cases of birth asphyxia.

\begin{tabular}{|l|l|c|}
\hline HIE stages & Cases & Mortality \\
\hline \multirow{2}{*}{ HIE I } & Neonatal sepsis with nectrotizing enterocolitis. & $1(0.12 \%)$ \\
\cline { 2 - 3 } & Preterm with hyline membrane disease and neonatal sepsis. & $1(0.12 \%)$ \\
\hline \multirow{3}{*}{ HIE II } & Neonatal sepsis & $4(26.66 \%)$ \\
\cline { 2 - 3 } & Hydrocephalus & $1(6.66 \%)$ \\
\hline \multirow{5}{*}{ HIE III } & Neonatal Sepsis & $2(22.22 \%)$ \\
\cline { 2 - 3 } & NNS with Pneumothorax & $2(22.22 \%)$ \\
\cline { 2 - 3 } & Preterm with Hyaline membrane disease & $4(44.44 \%)$ \\
\cline { 2 - 3 } & Meconium aspiration syndrome & $1(11.11 \%)$ \\
\hline
\end{tabular}

\section{Discussion}

In spite of major advances in monitoring technology and knowledge of fetal and neonatal pathologies, perinatal asphyxia or more appropriately, hypoxic ischemic encephalopathy (HIE) remain a serious condition, causing significant mortality and long term morbidity. It is a tragedy for a normally developed fetus to sustain cerebral injury during the last hours of intrauterine life and to exist for many years with major handicap. It is seen that for every early neonatal death, three disabled children survive. Birth asphyxia and the hypoxic ischemic encephalopathy are one of the common neonatal problems in our country. It is the commonest cause of hospital admission of a newborn ${ }^{10}$.

In this study 102 consecutive newborns delivered at Dhulikhel Hospital KUTH with birth asphyxia during 2 years and 9 months, were included. Birth asphyxia was diagnosed if there was a history of delayed crying at birth for more than 1 minute or if the 5 minute APGAR score was less than seven.

During this period, a total of 719 babies were admitted in the neonatal unit of which 102 (14.18\%) were admitted due to birth asphyxia. Our reported incidence of birth asphyxia (14\%) is almost similar to the incidence in the study carried out by Emmaneul Dzodeyan in Africa (40\%) $)^{11}$. The incidence of the birth asphyxia in the present study was low in compare to the study conducted by Daga ${ }^{12}$ in Kathmandu (27\%) and Azam in Pakistan (48\%) $)^{13}$. However the rate is quite high compared with the study by Lodakhi GM in India $(4.18 \%)^{14}$.

The asphyxia rate in this study was $26.95 / 1000$ live births. This result is high in number as compared with 5.4/1000 live hospital-born infant in Sweden ${ }^{3}$. This result is similar to $22 / 1000$ live hospital-born infants in a study from India ${ }^{5}$ and 12 college hospitals where the incidence was $21.92 \%{ }^{15}$.

In this study several maternal and fetal risk factor were also studied but as there was no control group of newborns without asphyxia born in Dhulikhel Hospital, we could not identify risk factors which were more prevalent in the study group than in pregnancies and deliveries of healthy infants.

In this study the largest numbers of babies affected by birth asphyxia were to mothers of 18-35 years $(78.43 \%)$ but this reflected the fact that this aged group represented as the most number of mothers in our obstetric service. So, this study showed that incidence of birth asphyxia was more common between 18-35 years and also shows that an increase or decrease in maternal age was not associated with any risk for birth asphyxia. This result was similar with another study done by Wael Hayel Kreisa and Zeiad Habaheh in Prince Ali Ben Al Hussein Hospital, Jordan ${ }^{16}$ in 2005 but different results from the study done by Rachalopantana Kerno et al at Paltani Hospital, Thailand ${ }^{17}$ showed that birth asphyxia was significantly related to maternal age greater than 30years.

Antenatal checkups were also studied. Only 16 women (15.68\%) had no check up during pregnancy, 62 women $(60.70 \%)$ had regular ANC in Dhulikhel Hospital and $24(23.52 \%)$ were having ANC in health post. This study showed less than one-fifth of the women of asphyxiated babies had no ANC check up during pregnancy. 
Out of the 102 newborns, 20 babies (19.60\%) were preterm 78 (48.47\%) were full term and 4 (3.92\%) were post term. The most of the birth asphyxia cases were term babies. This study is different from the statement that post maturity is an important risk factor of birth asphyxia ${ }^{13,18}$. This study is also different from the statement that prematurity is a significant risk factor for birth asphyxia. When total deliveries were considered, preterm babies were quite less then term babies. So if we consider only the preterm babies, birth asphyxia is common among them.

Out of the 102 mothers of asphyxiated babies, $60(58.82 \%)$ were primi gravida, $36(35.29 \%)$ had less than 5 children and 6 mothers $(5.88 \%)$ were having more than 5 children. So these figures show that birth asphyxia was more common in babies delivered by primi gravida. Similar result was shown by Azam M study done in Nishtar Medical College, Multan where the primigravida was shown to be $47 \%$. But this study didn't show increase incidence of birth asphyxia with grand multipara which is different from the study done by Azam $\mathrm{M}^{13}$ in Multan where the incidence was $34 \%$.

Certain maternal risk factors were assessed by maternal self-report made during admission. Among 60 mothers who had complications during pregnancy more than half of them had thick meconium stain. So, thick meconium stain liquor showed increase risk factor for birth asphyxia. This result was in contrast with the study done by Anne CC Lee et $\mathrm{al}^{19}$ at Southern Nepal which showed meconium stained amniotic fluid had a non significant greater risk for birth asphyxia (RR: 1.32, $95 \% \mathrm{Cl}: 0.19$ to 2.16$)$. This study is comparable with the study done by Lalsclottir $\mathrm{K}$ et $\mathrm{al}^{20}$ in Iceland where $50 \%$ of the women of asphyxiated babies had meconium stain amniotic fluid.

Among all the women of asphyxiated babies 21 (20.58\%) had premature rupture of membrane (PROM). Among the women with complicated pregnancy, more than one third had PROM. Study done by Anne CC Lee et al ${ }^{19}$ Southern Nepal and Azam $\mathrm{M}^{13}$ at Nishtar Hospital, Multan also showed that prolonged rupture of membrane was a significant risk factor for birth asphyxia. Ante partum haemmorrhage (APH) and maternal infection was accounted to be $5.68 \%$ and $11.76 \%$ respectively.

In this study birth asphyxia was commonly seen in those mothers who had no induction of labour than in those who had induction of labour. Only 28(27.45\%) mothers of asphyxiated babies had induction of labour. The finding in this study did agree with the finding at Pattani Hospital, Thailand ${ }^{17}$. While most deliveries
(51.96\%) were normal, some $(39.21 \%)$ had caesarean delivery and some $(8.82 \%)$ by vacuum.

Out of 102 babies, presenting with birth asphyxia $57(55.88 \%)$ were males and $45(44.11 \%)$ were females. This result is similar to the study done by Azam M in Multan ${ }^{13}$. Among the all 102 birth asphyxiated case $30.39 \%$ were $<2500 \mathrm{gm}, 50 \%$ were between $2500-3500$ gm and $19.60 \%$ were $>3000 \mathrm{gm}$. Among the total 102 cases of birth asphyxia $16(15.68 \%)$ cases died. This result is similar with the result shown in one study done by Lodakhi GM in India ${ }^{14}$. Only $2(2.60 \%)$ of HIE stage I, $5(33.33 \%)$ cases of HIE stage II and $9(90 \%)$ cases of HIE stage III died.

Overall mortality in cases of birth asphyxia (15.6\%) was similar to the study done by S.J Etuk and I.S. Etak ${ }^{21}$ in Nigra where mortality rate was $14.3 \%$. The mortality rate in this study was quite high as compare to the study done in University of Calabar Teaching Hospital $(p<0.001)$.

In this study mortality in HIE stage I and stage II was quite similar with the study done by M.H Haidary ${ }^{15}$ in Rajshahi, Bangaladesh but mortality in HIE stage III was higher than other studies like M.H Haidary in Rajshahi where the mortality was only $60 \%$. The result regarding incidence of mortality in different stages of HIE was similar with one study done by Lodakhi GM in India ${ }^{14}$. This result was also higher than another study done by Mullign and Chawdhary where mortality due to severe birth asphyxia was $25.87 \%$. In this study recovery rate in HIE stage I was $97.40 \%$, HIE stage II was $66.66 \%$ and HIE stage III was $10 \%$.

\section{Conclusion}

Birth asphyxia is one of the commonest causes of admission and mortality in NICU. Among all stages of birth asphyxia, HIE stage $I$ is the most common, then HIE stage II and finally HIE stagelll. Babies with HIE Stage III had a very poor prognosis where as HIE stage I had a very good prognosis. Sepsis is the commonest morbidity in cases of birth asphyxia. Low birth weight and preterm babies more commonly suffered from birth asphyxia. Maternal gravida, pregnancy complication with PROM, meconium, APH, emergency caesarean section, preterm and male sex were the risk factors for birth asphyxia. Mortality and morbidity were more common in males than in females.

All around the world, birth asphyxia is one of the commonest causes of neonatal deaths and also a major cause of neonatal admissions. Without proper understanding of the various risk factors and other 
associated factors related to birth asphyxia, it will be difficult to develop strategies for its prevention and management. The depth of researches on this matter in Nepal is no doubt a big limitation. This study sheds light to some of the aspects of birth asphyxia in a tertiary level setting in Nepal, although descriptive nature of this study is its main limitation. Prospective and case control studies will be necessary in future to get more scientific ideas about birth asphyxia in the context of Nepal.

Acknowledgement: none

Funding: none

Conflict of Interest: none

\section{References}

1. World Health organization. Basic Newborn Resuscitation; A Practical Guide. World Health Organization: Geneva 1997 [ Accessed February 27, 2007. Avilable http:www.who.int/reproductivehealth/publication/MSM 98 /introduction en.html.

2. Lawn JE, Cousens S, Zupan J.4 million neonatal deaths: when ? where? why? Lancet 2005;365:891900 .

3. Thornberg E, Thiringer K, Odeback A, Milson I. Birth Asphyxia; incidence, clinical course and outcome in a Swedish population. Acta Paediatr 1995;84:927-32.

4. Futrakul S, Praisawanna P, Thaitumyanon P. Risk factor for Hyposic- ischemic encephalopathy in asphysiated newborn infant. J Med Assoc Thai 2006;89:322-8.

5. Chandre S, Ramji S, Thirupurum S, Perinatal asphyxia; multivariate analysis of risk factors in haopital birth. Indian Pediatr 1997;34:206-12.

6. Nelson KB, Ellenberg J. Apgar scores as precidtors of chronic neurological disability. Pediatrics 1981;68:36-44.

7. Ellis M, Manandhar DS, Manandhar N, Wyatt J, Balam AJ, Costello AM stillbirths and neonatal encephalopathy in kathmandu, Nepal: An estimate of the contribution of birth asphyxia to perinatal mortality in low income urban population. Paediatr Perinat Epidermiol 2000;14:39-52.

8. Buchmann EJ, Pallinson RC, Myathikazi N.Intrapartum - related birth asphyxia in South Africa lessons from the first national perinatal care survey. S Af Med J 2002;92:897-901.
9. Richard E. Behrman, Robert M. Kliegman, Editors. Hypoxia-Ischemia, Nelson text book of pediatric 17th ed. United states of America. Hal B Jenson; 2004: 566-568.

10. Memon IA. Neonatal resuscitation. J Coll Physiol Surg Pak 1995;5(4):163-164.

11. Dzadeyan E, Study on maternal mortality \& neonatal morbidity in Africa, Rural intertated Relief Servive,Ghana 2007 http://www.who.int/pmnch/ topics/health_system/rirs_ghana/en/index.html. downloaded on 23/09/2010.

12. Daga As, Daga Sr, Patole SK. Risk assessment in birth asphyxia. Trop Pediatr 1990;36:34-39.

13. Azam M, Malik F,Khan P. Birth asphyxia risk factors. The professional 2004;11(4):416-423.

14. Ladakhi GM, Mubank M, Nabi B, Hassan M, Sethi AS. Neonatal risk factors and outcome of birth asphyxia. JK Practioner 2000;7(4):267-70.

15. Haidary $\mathrm{MH}$, Hussian $\mathrm{A}$, Ahmed $\mathrm{S}$, Kasem $\mathrm{A}$. Clinical profile of Birth asphyxia in Rajshahi medical collage hospital. J Teachers Assoc 2005;18: 106108.

16. Weal Hayel Khreisa, Zeiad Habahbeh, Risk factors of birth asphyxia: A study at Prince Ali Ben AlHussein Hospital Jod. Pak J Med Sci 2005;21(1):304.

17. Rachatapantanakorn $\mathrm{O}$, Tongkumchum $\mathrm{P}$, Chaisukant $Y$, Factor associated with birth asphyxia in Pattani Hospital Thailand. Songkla Med J 2005;23(1):17-27.

18. Gomella TL, Cunning MD, Perinatal asphyxia. The Professional 1999;480-89.

19. Anne CC-Lee et al, Risk Factors for Neonatal Mortality due to Birth Ashyxia in Southern Nepal. Pediatrics 2008;121(5):1381-90.

20. Lalsclottir K, Dagbjartsson A, Thorkellsson T, Hardottric $\mathrm{H}$; Birth asphyxia and hypoxic ischemic encephalopathy, incidence and obstetric risk factors. Laeknabladid 2007;93(9):595-60.

21. Etuk SJ, Etuk IS. Relative risk of birth asphyxia in babies of booked women who deliver in unorthodox health facilities in Calabor, Nigeria.Acta Tropica 2001;79(2):143-147.

\section{How to cite this article?}

Dongol S, Singh J, Shrestha S, Shakya A. Clinical Profile of Birth Asphyxia in Dhulikhel Hospital: A Retrospective Study. J Nep Paedtr Soc 2010;30(3):141-146. 